\title{
Pengaruh Keselamatan dan Kesehatan Kerja Terhadap Produktivitas Kerja Karyawan
}

\author{
Astiandini Hidayatullah ${ }^{1 *}$ dan Sri Surjani Tjahjawati ${ }^{2}$ \\ ${ }^{1}$ Jurusan Administrasi Niaga, Politeknik Negeri Bandung, Indonesia \\ ${ }^{2}$ Jurusan Administrasi Niaga, Politeknik Negeri Bandung, Indonesia
}

\begin{abstract}
:
This research was conducted to find out how the process of implementation of safety and health program in the production director detail part manufacturing division PT Dirgantara Indonesia, this research also can be known about work productivity at PT Dirgantara Indonesia. This research was conducted on 117 respondents who are employees of the production director detail part manufacturing division PT Dirgantara Indonesia. This study used primary data by using questionnaires and interviews also using secondary data obtained from books and journals. The classical principle test used for this research is normality test, heteroscedasticity test, and linearity test. The result is employee productivity in productivity direktorat production detail part manufacturing division PT Dirgantara Indonesia of $27.1 \%$ made by the implementation of health and safety programs as much as $72.9 \%$. The result of hypothesis test shows that there is a significant influence between the implementation of work safety program to the work productivity of the employees of the production directorate part part manufacturing PT Dirgantara Indonesia.
\end{abstract}

Keywords: safety, occupational health, occupational safety and health programs, productivity

\begin{abstract}
Abstrak:
Penelitian ini dilakukan untuk mengetahui bagaimana proses pelaksanaan program keselamatan dan kesehatan kerja di bagian produksi sutradara bagian manufaktur PT Dirgantara Indonesia, penelitian ini juga dapat diketahui tentang produktivitas kerja di PT Dirgantara Indonesia. Penelitian ini dilakukan pada 117 responden yang merupakan karyawan direktur produksi detil divisi manufaktur PT Dirgantara Indonesia. Penelitian ini menggunakan data primer dengan menggunakan kuesioner dan wawancara juga menggunakan data sekunder yang diperoleh dari buku dan jurnal. Uji prinsip klasik yang digunakan untuk penelitian ini adalah uji normalitas, uji heteroskedastisitas, dan uji linieritas. Hasilnya adalah produktivitas karyawan dalam produktivitas direktorat produksi secara detail bagian manufaktur PT Dirgantara Indonesia sebesar $27,1 \%$ dilakukan dengan program kesehatan dan keselamatan sebanyak $72,9 \%$. Hasil uji hipotesis menunjukkan bahwa terdapat pengaruh yang signifikan antara pelaksanaan program keselamatan kerja terhadap produktivitas kerja karyawan bagian produksi direktorat bagian bagian manufaktur PT Dirgantara Indonesia.
\end{abstract}

Kata Kunci: keselamatan kerja, kesehatan kerja, program keselamatan dan kesehatan kerja, produktifitas

*Email Korespondensi: Astiandini Hidayatullah astiandinih@gmail.com

Jurnal Riset Bisnis \& Investasi

Vol. 3, No. 2, Agustus 2017

ISSN 2460-8211

\section{PENDAHULUAN}

Keselamatan dan Kesehatan Kerja (K3) merupakan hal yang penting bagi perusahaan, karena dampak kecelakaan

104 
kerja tidak hanya merugikan karyawan, tetapi juga perusahaan. Perusahaan harus menanggung biaya pengobatan dan biaya rumah sakit atau bahkan menanggung biaya penguburan jika korban meninggal dunia, hilangnya waktu kerja karyawan yang menjadi korban dan rekan-rekan karyawannya yang ikut menolong sehingga menghambat kelancaran kerja, merekrut karyawan baru dan memberi pelatihan dan juga dapat menurunkan mental atau kondisi psikis para karyawan lainnya. Sedangkan kerugian yang terjadi bagi karyawan adalah karyawan dapat mengalami luka-luka, cacat fisik dan meninggal dunia. Maka dari itu keselamatan dan kesehatan kerja merupakan suatu program yang dibuat oleh pemerintah yang harus dipatuhi dan dilaksanakan guna mencegah timbulnya kecelakaan. Hal ini bertujuan untuk dapat menciptakan tempat kerja yang nyaman dan sehat sehingga dapat mengurangi resiko kecelakaan kerja.

Keselamatan dan kesehatan kerja termasuk salah satu program pemeliharaan yang ada di perusahaan. Pelaksanaan program keselamatan dan kesehatan kerja bagi karyawan sangat penting karena bertujuan untuk menciptakan sistem keselamatan dan kesatuan kerja dengan melibatkan unsur manajemen, tenaga kerja, kondisi dan lingkungan kerja yang terintegrasi dalam rangka mengurangi kecelakaan. Salah satu penyebab terjadinya kecelakaan kerja adalah pelaksanaan dan pengawasan program kesehatan dan keselamatan kerja yang belum maksimal. Apabila program keselamatan dan kesehatan kerja terlaksana dengan baik, maka kasus kecelakaan kerja dapat dihindari sehingga dapat tercapai suasana kerja yang aman, nyaman, sehat, dan tercapai produktivitasnya.

Sebagai perusahaan pesawat terbang PT Dirgantara Indonesia tentu menggunakan mesin - mesin yang dapat menimbulkan potensi bahaya yang dapat mengancam keselamatan dan kesehatan para karyawannya diantaranya seperti mesin pemotong, pengecoran, mesin bonding serta adanya penggunaan bahan bahan kimia dalam proses produksi. Dengan demikian, kehati - hatian karyawan dalam menggunakan alat atau mesin yang digunakan dalam proses produksi sangatlah diperlukan demi keselamatan kerja karyawan tersebut. PT Dirgantara Indonesia telah menerapkan sistem keselamatan dan kesehatan kerja yang dilaksanakan sesuai dengan tingkat resiko masing - masing seperti melengkapi karyawannya dengan pakaian khusus bengkel (wearpack), savety shoes, penutup telinga, kacamata khusus dan masker. Kecelakaan industri secara umum disebabkan oleh 2 hal pokok yaitu perilaku kerja yang berbahaya (Unsafe Acts) dan kondisi yang berbahya (Unsafe Condition). Berdasarkan data monitoring kecelakaan kerja di PT Dirgantara Indonesia (Persero) pada tahun 2015 hingga 2017 masih ditemukan kasus kecelakaan kerja hal tersebut didapatkan berdasarkan keterangan pihak Keselamatan dan kesehatan kerja Lingkungan Hidup (K3LH) PT Dirgantara indonesia. Menurut keterangan pengawas K3LH PT Dirgantara Indonesia sebagian besar kecelakaan terjadi akibat kelalaian karyawan. Hal tersebut diperkuat dengan ditemukannya karyawan yang tidak menggunakan alat keamanan sebagaimana telah diatur oleh perusahaan, mereka tidak patuh akan peraturan seperti mengoperasikan mesin tanpa menggunakan wearpack, kacamata dan savety shoes hal tersebut tentu dapat membahayakan bagi karyawan terlebih jika terjadinya kecelakan yang juga akan berdampak pada produktivitas perusahaan.

Berdasarkan uraian latar belakang masalah sebelumnya, maka identifikasi masalah dalam penelitian ini adalah sebagai berikut: 
1. Bagaimana Keselamatan dan Kesehatan Kerja (K3) pada Divisi Detail Part Manufacturing Direktorat Produksi PT Dirgantara Indonsesia (Persero).

2. Bagaimana produktivitas kerja karyawan pada Divisi Detail Part Manufacturing Direktorat Produksi PT Dirgantara Indonsesia (Persero).

3. Berapa besar pengaruh pelaksanaan program Keselamatan dan Kesehatan Kerja (K3) terhadap produktivitas kerja karyawan pada Divisi Detail Part Manufacturing Direktorat Produksi PT Dirgantara Indonsesia (Persero).

\section{KAJIAN LITERATUR}

\section{Keselamatan dan Kesehatan Kerja (K3)}

Keselamatan kerja merupakan suatu bentuk keadaan yang menghindarkan kesalahan dan kerusakan kerja yang dilakukan oleh pekerja/ karyawan (Widodo, 2015: 240). Pada dasarnya keselamatan merupakan kebutuhan setiap manusia dan menjadi naluri dari setiap makhluk hidup sejak manusia bermukim di muka bumi, secara tidak sadar mereka telah mengenal aspek keselamatan untuk mengantisipasi berbagai bahaya di sekitar lingkungan hidupnya (Ramli, 2010: 6). Sementara menurut Kautsar, Swasto dan Musadieq (2013: 3) keselamatan kerja adalah suatu bentuk perlindungan yang berkaitan dengan upaya pencegahan kecelakaan kerja maupun lingkungan kerja serta tindakan pekerja sendiri. Dari ketiga pendapat tersebut dapat disimpulkan bahwa keselamatan kerja merupakan kebutuhan manusia untuk menghindarkan serta melindungi pekerja dari kecelakaan dan bahaya.

Kesehatan kerja adalah suatu kondisi kesehatan yang bertujuan agar masyarakat pekerja memperoleh derajat kesehatan setinggi tingginya, baik jasmani, rohani, maupun sosial, dengan usaha pencegahan dan pengobatan terhadap penyakit atau gangguan kesehatan yang disebabkan oleh pekerjaan dan lingkungan kerja maupun penyakit umum (Widodo, 2015: 244). Sementara Kesehatan kerja menurut Asmui, Hussin \& Paino (2012: 290) adalah bagian dari ilmu kesehatan yang bertujuan agar tenaga kerja memperoleh keadaan kesehatan yang sempurna baik fisik, mental maupun sosial. Hartatik (2014: 315) mengemukakan bahwa "kesehatan kerja merupakan suatu kondisi kesehatan yang bertujuan agar pekerja memperoleh derajat kesehatan setinggi-tingginya, baik jasmani, rohani, maupun sosial, dengan usaha pencegahan dan pengobatan terhadap penyakit atau gangguan kesehatan yang disebabkan oleh pekerjaan dan lingkungan kerja maupun penyakit umum". Dari beberapa pendapat tersebut maka diketahui bahwa kesehatan kerja merupakan kondisi kondisi tenaga kerja yang baik, entah dari segi fisik maupun mental.

Menurut Fajar dan Heru (2010: 206), keselamatan dan kesehatan kerja menunjuk pada kondisi fisiologis fisik dan psikologi tenaga kerja yang diakibatkan oleh lingkungan kerja perusahaan. Keselamatan dan kesehatan kerja adalah pengawasan terhadap orang, mesin, material dan metode yang mencakup lingkungan kerja agar pekerja tidak mengalami cidera, Sedarmayanti (2010: 208).

\section{Produktivitas Kerja}

Menurut Stevenson dan Chuong (2015: 55) Produktivitas (productivity) adalah indeks yang mengukur output (barang dan jasa) dibandingkan dengan input (tenaga kerja, bahan baku, energi dan sumber daya yang lainnya) yang digunakan untuk memproduksi output. Pernyataan serupa dinyatakan oleh Heizer dan Render (2015: 9) yang menjelaskan bahwa produktivitas (productivity) merupakan rasio hasil 
(barang dan jasa) dibagi dengan masukan (sumber daya seperti buruh dan modal).

Produkivitas adalah ukuran efisiensi produk. Suatu perbandingan antara hasil keluaran dan masukan. Masukan sering ditandai dengan tenaga kerja sementara keluaran diukur dalam satuan fisik, bentuk dan nilai (Sutrisno, 2015). Jika melihat pendapat mengenai pengertian dari produktivitas kerja maka dapat disimpulkan bahwa produktivitas merupakan perbandingan antara output dan input dan akan menghasilkan efisiensi produk. Sulistiyani (2009) menambahkan bahwa Produktivitas kerja menyangkut masalah hasil akhir, yakni seberapa besar hasilnya yang diperoleh dalam proses produksi. Berdasarkan pendapat tersebut maka dapat diketahui bahwa produktivitas merupakan hasil yang mampu dicapai tenaga kerja selama proses produksi. Metode yang digunakan dalam penelitian ini adalah metode kuantitatif yang artinya penelitian yang berlandaskan pada filsafat positivisme, digunakan untuk meneliti pada populasi atau sampel tertentu, teknik pengambilan sampel pada umumnya dilakukan dengan secara random, pengumpulan data menggunakan instrumen penelitian, analisis data bersifat kuantitatif/statistik dengan tujuan untuk menguji hipotesis yang telah ditetapkan (sugiyono, 2010: 13).

\section{METODE PENELITIAN}

Populasi pada penelitian ini didapat dari jumlah karyawan yang bekerja pada Direktorat Produksi Divisi Detail Part Manufacturing yaitu sebanyak 164 orang. Sampel yang didapat dari jumlah populasi 164 orang adalah sebanyak 117 orang, jumlah tersebut didapat dengan menggunakan rumus solvin dengan taraf kesalahan $5 \%$.

Penelitian ini menggunakan dua sumber data yaitu data primer dan data sekunder. Dalam penelitian ini data primer meliputi informasi mengenai pelaksanaan program K3 dan produktivitas kerja karyawan yang diperoleh melalui kuesioner yang dibagikan kepada responden di direktorat produksi divisi detail part manufacturing PT Dirgantara Indonesia (Persero). Selain dari menyebarkan kuesioner kepada responden data yang didapat juga diperkuat dengan melakukan wawancara kepada narasumber yang memiliki kaitan erat dengan informasi yang dibutuhkan. Data sekunder dalam penelitian ini didapat dari buku, jurnal, skripsi serta literatur yang berkaitan dengan permasalahan yang diperlukan untuk melakukan penelitian ini.

\section{Analisis Deskriptif}

Nilai mean dari variabel produktivitas seperti yang nampak pada Tabel 1 adalah sebesar 4,12 atau berada dalam rentang 3,40 - 4,19 yang artinya baik. Nilai standar deviasi variabel produktivitas adalah sebesar 0,431 atau $10,46 \%$ dari nilai mean, nilai standar deviasin dari variabel produktivitas tidak sampai $20 \%$ sehingga dapat diketahui bahwa variasi jawaban yang diberikan responden untuk variabel ini.

Tabel 1 Deskriptif Analisis

\begin{tabular}{|c|c|c|}
\hline Pernyataan & $\begin{array}{c}\text { Rata- } \\
\text { Rata }\end{array}$ & $\begin{array}{l}\text { Standar } \\
\text { Deviasi }\end{array}$ \\
\hline \multicolumn{3}{|c|}{ Keselamatan dan Kesehatan Kerja (X) } \\
\hline $\begin{array}{l}\text { Dimensi Pengukuran dan } \\
\text { Pengawasan }\end{array}$ & 4,08 & 0,708 \\
\hline Dimensi Pencegahan Kecelakaan & 3,99 & 0,639 \\
\hline Dimensi Pencegahan Penyakit & 4,04 & 0,577 \\
\hline Dimensi Manajemen Tekanan & 3,76 & 0,765 \\
\hline Dimensi Program Kesehatan & 3,84 & 0,715 \\
\hline Rata - Rata & 3,94 & 0,556 \\
\hline \multicolumn{3}{|c|}{ Produktivitas Kerja Karyawan (Y) } \\
\hline Dimensi Knowledge & 3,95 & 0,705 \\
\hline Dimensi Skills & 4,14 & 0,503 \\
\hline Dimensi Abilities & 4,15 & 0,476 \\
\hline Dimensi Attitude & 4,10 & 0,549 \\
\hline Dimensi Behaviors & 4,11 & 0,454 \\
\hline Rata - Rata & 4,12 & 0,431 \\
\hline
\end{tabular}


Dari Tabel 1 dapat diketahui bahwa variabel keselamatan dan kesehatan kerja memiliki jawaban responden terendah 1 dan jawaban responden tertinggi 5. Nilai mean untuk variabel keselamatan dan kesehatan kerja adalah sebesar 3,94 yang artinya berada pada interval 3,4-4,19 yang artinya baik.

Tabel 2 Hasil Uji Korelasi

\begin{tabular}{|l|l|c|c|}
\hline & & $\mathrm{K} 3$ & Produktivitas \\
\hline K3 & $\begin{array}{l}\text { Pearson } \\
\text { Correlation }\end{array}$ & 1 & $0,521^{* *}$ \\
\hline & Sig. (2-tailed) & & 0,000 \\
\hline & N & 117 & 117 \\
\hline Produktivitas & $\begin{array}{l}\text { Pearson } \\
\text { Correlation }\end{array}$ & $0,521^{* *}$ & 1 \\
\hline & Sig. (2-tailed) & 0,000 & \\
\hline & N & 117 & 117 \\
\hline
\end{tabular}

**. Correlation is significant at the 0.01 level (2tailed).

Sumber: Olah Data SPSS (2017)

\section{Analisis Korelasi}

Analisis korelasi dilakukan untuk mengetahui derajat hubungan antara variabel bebas dengan hubungan terikat. Hasil uji korelasi yang tercantum dalam tabel 2 menunjukan bahwa korelasi dari kedua variabel adalah sebesar 0,521 dan jika mengacu pada interpretasi nilai korelasi yang dikemukakan oleh Sugiono (2013: 25) 0,521 berada pada rentang skala $0,40-0,599$ yang artinya korelasi antar kedua variabel sedang.

Tabel 3 Hasil Analisis Regresi Linier Sederhana

\begin{tabular}{|l|r|r|c|r|c|}
\hline \multirow{2}{*}{ Model } & \multicolumn{2}{|c|}{$\begin{array}{c}\text { Unstandardized } \\
\text { Coefficients }\end{array}$} & $\begin{array}{c}\text { Standardized } \\
\text { Coefficients }\end{array}$ & \multirow{2}{*}{ T } & \multirow{2}{*}{ Sig. } \\
\cline { 2 - 5 } & \multicolumn{1}{|c|}{$\mathrm{B}$} & Std. & Bet & & \\
\hline (Constant) & 35,321 & 3,440 & & 10,267 &, 000 \\
\cline { 2 - 6 } K3 &, 314 &, 048 &, 521 & 6,547 &, 000 \\
\hline
\end{tabular}

Sumber: Olah Data SPSS (2017)

Dari Tabel 3 kita dapat mengetahui mengenai perumusan regresi untuk mengetahui pengaruh keselamatan dan kesehatan kerja terhadap produktivitas.
Dari data tersebut maka diketahui bahwa nilai konstanta (a) sebesar 35,321 dan nilai koefisien regresi (b) sebesar 0,314 Maka dari itu, diperoleh persamaan regresi sebagai berikut:

$$
\begin{aligned}
& \mathrm{Y}=\mathrm{a}+\mathrm{b} X \\
& \mathrm{Y}=35,321+0,314 X
\end{aligned}
$$

Dari persamaan regresi linier sederhana tersebut dapat diketahui bahwa setiap penambahan satu angka keselamatan dan kesehatan kerja dengan koefisien regresi bernilai positif, maka Produktivitas akan meningkat sebesar 0,314 .

\section{Koefisien Determinasi}

Koefisien determinasi bertujuan untuk mengetahui seberapa besar variasi perubahan dalam satu variabel terkait yang ditentukan oleh perubahan dalam variabel bebas (Silalahi, 2012: 376). Koefisien determinasi sendiri merupakan kuadrat dari koefisien korelasi $\left(\mathrm{R}^{2}\right)$.

\section{Tabel 4. Koefisien Determinasi}

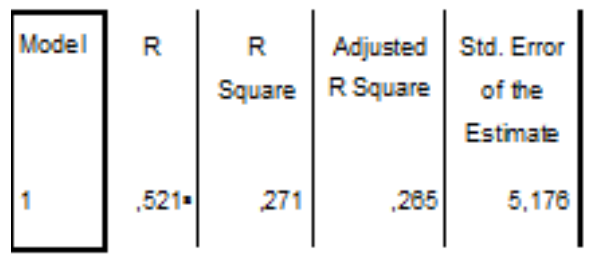

Sumber: Olah data SPSS

Dapat dilihat dalam Tabel 4 bahwa nilai $\mathrm{R}$ Square yang tertera adalah 0,271 atau $27,1 \%$, yang artinya produktivitas kerja karyawan di PT Dirgantara Indonesia 27,1\% dipengaruhi oleh program keselamatan dan kesehatan kerja karyawan. Sisanya atau sebanyak $72,9 \%$ dipengaruhi oleh faktor lain di luar penelitian ini.

\section{Uji Hipotesis}

Jika merujuk pada Tabel 5 dapat diketahui bahwa didapat nilai $F_{o}$ sebesar 42,857 dan sig 0,000 . Nilai signifikansi yang tercantum pada tabel 4.22 lebih kecil 
dibandingkan dengan nilai probabilitasnya yaitu sebesar $5 \%$ atau 0,05 .

Tabel 5 Uji Statistik F

\begin{tabular}{|l|l|c|c|c|c|}
\hline \multicolumn{1}{|c|}{ Model } & $\begin{array}{l}\text { Sum of } \\
\text { Squares }\end{array}$ & Df & $\begin{array}{c}\text { Mean } \\
\text { Square }\end{array}$ & F & Sig. \\
\hline Regression & 1148,269 & 1 & 1148,26 & 42,85 &, $000^{\mathrm{b}}$ \\
\hline Residual & 3081,184 & 115 & 26,79 & & \\
\hline Total & 4229,453 & 116 & & & \\
\hline
\end{tabular}

Sumber : Olah data SPSS (2017)

Dari nilai $\mathrm{F}_{\mathrm{o}}$ yang telah didapat yaitu sebesar 42,857 maka perlu diketahui nilai $\mathrm{Ft}$ dengan cara mencari nilai N1 dan N2 terlebih dahulu, $\mathrm{N} 1=\mathrm{K}-1$ dimana $\mathrm{k}$ adalah jumlah variabel sehingga didapat $2-1=1$ dan untuk N2 $=\mathrm{n}-\mathrm{k}$ dimana $\mathrm{n}$ adalah jumlah responden maka didapat $117-2=115$. Perhitungan tersebut didapat nilai $F_{t}$ sebesar 3,92. Jika merujuk pada interpretasi pengambilan keputusan hasil uji stastistik $F$ yang dikemukaka oleh Arikunto (2010: 268) yaitu $\mathrm{F}_{0} \geq \mathrm{F}_{\mathrm{t}}$ atau $42,857 \geq 3,92$ yang artinya $\mathrm{H}_{0}$ ditolak dan $\mathrm{H}_{\mathrm{a}}$ diterima. Kesimpulannya pelaksaanaan program keselamatan dan kesehatan kerja di PT Dirgantara Indonesia berpengaruh signifikan terhadap produktiitas kerja karyawan PT Dirgantara Indonesia.

\section{Uji Statistik T}

Uji statistik $\mathrm{T}$ dilakuan untuk mengetahui seberapa jauh pengaruh suatu variabel penjelas secara individual memperjelas variasi variabel terikat (Sugiyono, 2013: 136). Dasar dalam pengambilan keputusan uji statistik T yang dikemukakan Arikunto (2010:368) adalah jika thitng $>t_{\text {tabel }}$ dengan $\mathrm{p}<0,05$ maka $\mathrm{H}_{0}$ ditolah dan $\mathrm{H}_{\mathrm{a}}$ diterima. Jika di lihat pada tabel 11 didapat $t_{\text {hitung }}$ sebesar 6,547 dan sig 0,000 . Dari nilai tersebut maka $t_{\text {tabel }}=117$ $2=115$ sehingga diperoleh nilai $t_{\text {tabel }}$ sebesar 1,98081 yang mana 6,547 $\geq$ 1,98081 dengan signifikansi $0,000<0,05$.

Sehingga hasil uji statistik yang tertera pada Tabel 6 menunjukan bahwa, pelaksanaan program keselamatan dan kesehatan kerja karyawan berpengaruh signififkan terhadap produktivitas kerja karyawan PT Dirgantara Indonesia.

Tabel 6 Hasil Uji Statistik T

\begin{tabular}{|c|c|c|c|c|c|}
\hline \multirow[t]{2}{*}{ Model } & \multicolumn{2}{|c|}{$\begin{array}{c}\text { Unstandardized } \\
\text { Coefficients }\end{array}$} & $\begin{array}{c}\text { Standardized } \\
\text { Coefficients }\end{array}$ & \multirow[t]{2}{*}{$\mathrm{T}$} & \multirow[t]{2}{*}{ Sig. } \\
\hline & B & $\begin{array}{l}\text { Std. } \\
\text { Error }\end{array}$ & Beta & & \\
\hline (Constant) & 35,321 & 3,440 & & 10,26 &, 000 \\
\hline K3 &, 314 & ,048 &, 521 & 6,547 &, 000 \\
\hline
\end{tabular}

\section{PEMBAHASAN}

Setelah melakukan pengujian terhadap 117 orang responden didapat hasil bahwa terdapat hubungan positif antara pelaksanaan program keselamatan dan kesehatan kerja terhadap produktivitas kerja karyawan, hal itu mengacu pada interpretasi nilai korelasi yang dikemukakan oleh Sugiono (2013: 25) nilai korelasi antara pelaksanaan K3 terhadap produktivitas kerja adalah sebesar 0,521 atau berada dalam rentang 0,40-0,599.

Pelaksanaan program K3 memiliki pengaruh terhadap produktivitas kerja karyawan, hal ini dibuktikan oleh hasil uji regresi sederhana yang telah dilakukan dan menghasilkan konstanta $(\alpha)$ sebesar 35,321 dengan koefisien regresi (b) sebesar 0,314 sehingga didapatlah persamaan $\mathrm{Y}=35,321$ $+0,314 \mathrm{X}$. Berdasarkan persamaan regresi tersebut diketahui bahwa setiap penambahan satu angka keselamatan dan kesehatan kerja dengan koefisien regresi bernilai positif, maka produktivitas akan meningkat sebesar 0,314. Sedangkan jika nilai keselamatan dan kesehatan kerja nol maka nilai produktivitas senilai 35,321.

Hasil koefisien determinasi menunjukan bahwa nilai $\mathrm{R}$ Square sebesar 0,271 atau $27,1 \%$ yang artinya produktivitas kerja karyawan divisi detai part manufacturing direktorat produksi PT Dirgantara Indonesia dipengaruhi oleh pelaksanaan program keselamatan dan 
kesehatan kerja sebesar $27,1 \%$ sementara sisanya yaitu sebesar $72,9 \%$ dipengaruhi oleh faktor/variabel lain yang tidak dijelaskan dalam penelitian ini. Pelaksanaan program keselamatan dan kesehatan kerja memiliki pengaruh yang signifikan terhadap prodiktivitas kerja karyawan direktorat produksi divisi detail part manufacturing PT Dirgantara Indonesia, hal tersebut dibuktikan oleh hasil uji hipotesis dengan menggunakan uji statistik F dan uji statistik t. Uji statistik F, menunjukan bahwa nilai $\mathrm{F}$ hitung sebesar 42,857 dan didapat nilai $F$ tabel sebesar 3,92. Berdasarkan data tersebut, diketahui bahwa nilai $\mathrm{F}$ hitung lebih besar dari $\mathrm{F}$ tabel, selain itu diketahui pula nilai signifikansi sebesar 0,000 (lebih kecil dari 0,05). Sehingga, dapat disimpulkan bahwa Ho ditolak dan Ha diterima, Hal tersebut menunjukkan bahwa pelaksaaan program keselamatan dan kesehatan kerja berpengaruh signifikan terhadap produktivitas kerja karyawan.

Berdasarkan uji $\mathrm{t}$, diperoleh nilai $\mathrm{t}$ hitung sebesar 6,547 dan diperoleh nilai t tabel sebesar 1,98081. Berdasarkan data tersebut, diperoleh nilai t hitung yang lebih besar dari t tabel (6,547> 1,98081). Angka signifikansi sebesar 0,000 , nilai tersebut lebih kecil dibandingkan dengan nilai probabilitasnya yang nilainya sebesar 0,05 atau $5 \%(0,05>0,000)$. Bila mengacu pada pendapat Priyatno (2013: 114) yang menyatakan bahwa jika kriteria $\mathrm{t}$ hitung $>\mathrm{t}$ tabel dan tingkat signifikansi $<0,05$, maka interpretasinya adalah $\mathrm{H}_{\mathrm{o}}$ ditolak dan $\mathrm{H}_{\mathrm{a}}$ diterima. Hal tersebut menunjukan bahwa pelaksaaan program keselamatan dan kesehatan kerja berpengaruh signifikan terhadap produktivitas kerja karyawan.

\section{KESIMPULAN DAN SARAN Kesimpulan}

1. Pelakasanaan program keselamatan dan kesehatan kerja di direktorat produksi divisi detail part manufacturing PT Dirgantara Indonesia sudah dilaksanakan dengan baik.

2. Produktivitas kerja karyawan direktorat produksi divisi detail part manufacturing PT Dirgantara Indonesia sudah baik.

3. Pelaksanaan program keselamatan dan kesehatan kerja memiliki pengaruh yang signifikan terhadap prodiktivitas kerja karyawan direktorat produksi divisi detail part manufacturing PT Dirgantara Indonesia.

\section{Saran}

1. Pelaksanaan program keselamatan dan kesehatan kerja di Direktorat Produksi Divisi Detail Part Manufacturing PT Dirgantara Indonesia dinilai sudah baik, namun jika ditingkatkan agar menjadi lebih baik.

2. Produktivitas kerja karyawan dinilai sudah baik, namun perlu di tingkatkan agar dapat lebih baik lagi, salah satunya dengan memberi reward jika produksi memenuhi target dan tanpa ada reject.

\section{DAFTAR PUSTAKA}

Al Kautsar, I., Swasto, B. \& Al Musadieq, M. (2013). Pengaruh Keselamatan dan Kesehatan Kerja terhadap Kinerja Karyawan. Jurnal Administrasi Bisnis Volume 6 no.2. Malang: Fakultas Ilmu Administrasi Universitas Brawijaya

Arikunto, S. (2010). Prosedur Penelitian Suatu Pendekatan Praktik. Jakarta: Rineka Cipta.

Asmui. M., Hussin. A., \& Paino. H. (2012). The Importance of Work Environment Facilities International Journal of Learning \& Development ISSN 2164-4063 2012, Vol. 2, No. 1289 
Hartatik, I. P. (2014). Buku Praktis Mengembangkan SDM. Yokyakarta: Laksana.

Heizer, J. \& Barry R. (2015). "Manajemen Operasi: Keberlangsungan dan Rantai Pasokan". Edisi Sebelas. Diterjemahkan oleh: Hirson Kurnia, Ratna Saraswati, David Wijaya. Jakarta: Salemba Empat.

Jackson, R. S. S. \& Werner, S. (2011). Pengelolaan Sumber Daya Manusia edisi kesepuluh. Jakarta: Salemba Empat

Priyatno, D. (2013). Mandiri Belajar SPSS untuk pemula. Cetakan Pertama, Jakarta: Mediakom.
Ramli, S. (2010). Sistem Manajemen Keselamatan dan Kesehatan Kerja OHSAS 18001. Jakarta: Dian Rakyat.

Silalahi, U. (2012). Metode Penelitian Sosial. Bandung: Refika Aditama.

Stevenson, W. J. \& Chuong, S. C. (2015). Manajemen Operasi: Perspektif Asia. Edisi 9. Buku 1. Diterjemahkan oleh: Diana Angelica, David Wijaya dan Hirson Kurnia. Jakarta: Salemba Empat.

Sugiyono. (2010). Metode Penelitian Pendidikan Pendekatan Kuantitatif, Kualitatif, dan R\&D. Bandung: Alfabeta. 